\title{
The Status of Uber Drivers: A Purposive Approach
}

\author{
GuY DAVIDOV
}

Recibido: 04.03.2017

Aceptado: 16.05 .2017

https://doi.org/10.20318/sllerj.2017.3921

\begin{abstract}
The status of Uber drivers - the question of whether they are independent contractors (as argued by Uber) or employees - has been the subject of a heated debate recently. The goal of this paper is to address this question at the normative level: what should the law be in this regard? It begins, in part II, by briefly discussing some preliminary issues about how to address the problem: does it make sense to retain the employee/independent contractor distinction at all? Is it justified to maintain an "all or nothing" dichotomy? Should we leave the determination of "who is an employee" to courts? And finally, how should we interpret the term "employee" that appears in legislation? As will become clear, my approach is purposive, and Part III outlines - based on my previous writings - what this means in the context of identifying an employment relationship that justifies the application of labour laws. I will briefly consider several goals of labour law, and suggest that the most useful level of abstraction for current purposes is to focus on the unique vulnerabilities of employment, which I identify as democratic deficits (subordination, broadly conceived) and dependency (economic as well as for social/psychological needs). Finally, part IV applies these general principles to the specific context of Uber drivers, concluding eventually that Uber drivers should be considered employees.
\end{abstract}

Keywords: employee, independent contractor, Uber, gig economy, on demand.

\section{Introduction}

The status of Uber drivers has been the subject of a heated debate recently. This transportation service - which ingeniously connects drivers with customers through an online app - is highly popular especially with residents of big cities, both those (customers) who use it as a cheap and efficient taxicab, and those (drivers) who enjoy the opportunities it creates for extra income. There is little doubt that such a service offers some gains to society. At the same time, it is quite obvious that the use of new technologies cannot be a valid excuse for evading the law. Thus, for example, if a legal system requires taxicab drivers to obtain a license to be able to drive people commercially, and only under certain conditions, it would be

\footnotetext{
*Elias Lieberman Professor of Labour Law, Hebrew University of Jerusalem. Thanks to professors Jesús R. Mercader Uguina, Francisco Javier Gómez Abelleira and Ana Belén Muñoz Ruiz for the invitation to write this paper for a special issue of the Spanish Labour Law and Employment Relations Journal and to present it at a workshop on the sharing economy in Universidad Carlos III de Madrid. Thanks also to the participants at the workshop for their helpful comments.
} 
silly to allow some people an exception from this law just because the taxicab is called Uber, or because the car is used also for private purposes, or because the service is booked online rather than by phone.

The same is true with regard to the status of drivers - the question of whether they are independent contractors (as argued by Uber) or employees. If the protection of labour law is needed in such cases, the use of new technologies such as an online platform should not matter; it cannot be a valid excuse for evading the law. ${ }^{1}$ Nonetheless, the relationship between Uber and its drivers is also based on a somewhat new model of work organization, which raises a valid question as to their status. The goal of this paper is to address this question at the normative level. I will not try to fully describe or assess the current state of the law, but rather ask: what should the law be in this regard?

The discussion is also relevant to numerous other companies which, like Uber, connect buyers and sellers of services (or work time) online. Many different names have been proposed to this phenomenon, including the sharing economy, croudsourcing/crowdworking, the gig economy, platforms and so on. Personally I prefer the term "on-demand" work, at least for current purposes, as it points attention to the most important aspect in terms of work organization. ${ }^{2}$ I will therefore use this term below, without getting into a debate on the most appropriate term. The discussion is relevant to "on-demand" workers in general, but I will rely on the facts relevant to Uber (at least as it operates in the United States and the United Kingdom) so application to other cases might require some modification depending on their own factual details.

It is important not to overstate, and at the same time not to underestimate, the magnitude of the problem. The "on demand" economy may be revolutionary in some respects (Lobel, 2016) but in the current context the challenges it creates are not unlike those we have already been struggling with for many years (Finkin, 2016; De Stefano, 2016). These challenges certainly require discussion, and justify debates regarding the best way to address the new problems, but there is no reason to see them as paradigm-shifting. Moreover, although the "on demand" sector is growing, it is important to remember that it still represents only a small fraction of the labour market (estimated in the United States at $0.5 \%$ of all workers as of 2015; see Katz and Krueger, 2016). It is certainly significant and justifies the interest it has generated, but at the same time has to remain in context; for example, we should not change our general understanding of employer-employee relations in light of the experience of $0.5 \%$ of the workers, if this might negatively impact the other $99.5 \%$.

The paper proceeds as follows. It begins, in part II, by briefly discussing some preliminary issues about how to address the problem: does it make sense to retain the employee/independent contractor distinction at all? Is it justified to maintain an "all or nothing" dichotomy? Should we leave the determination of "who is an employee" to courts? And finally, how should we interpret the term "employee" that appears in legislation? As will become clear, my approach is purposive, and Part III outlines what this means in the context of identifying an employment relationship that justifies the application of labour laws. I will briefly consider several goals of labour law, and suggest that the most useful level of abstraction for current purposes is to focus on the unique vulnerabilities of employment, which I identify as democratic deficits (subordination, broadly conceived) and dependency (economic as well as for social/ psychological needs). Finally, part IV applies these general principles to the specific context of Uber drivers, concluding eventually that Uber drivers should be considered employees. ${ }^{3}$

The main advantage of a purposive approach is that it avoids technical-legalistic application of tests that could be outdated, instead looking for the ultimate goals behind labour laws - and consequently behind the distinction between "employees" and independent contractors - to decide who should be protected. By the very nature of this approach, then, it is well suited to deal with new forms of work arrangements. I will attempt to show that if a purposive approach is applied, it can address the challenge of "on demand" work arrangements, without the need to invent new solutions.

\footnotetext{
${ }^{1}$ I use the term labour law in this article in the broad sense, including what North American call employment law and workplace discrimination law.

${ }^{2}$ For a useful typology and overview of different online platforms see Signes, 2017.

${ }^{3}$ Parts I and II are based on my previous writings, which culminated recently in Davidov (2016). Part III and the structure of this paper as a whole are based on a series of three posts that I published on May 2016 in the blog www.onlabor.org. The current version is updated and expanded.
} 


\section{Some preliminary questions}

Before moving to consider directly whether Uber drivers should be classified as employees, we have to acknowledge some preliminary issues. First, does it make sense to retain the employee/independent contractor distinction at all? Surely the "on demand" economy in itself cannot lead one to suggest otherwise. However, the rise of this new model of work is part of a much larger phenomenon, the shift to "alternative" work arrangements which depart from the traditional model. Although hardly new, this trend continues to grow in magnitude; in the United States, for example, it has recently been estimated that the percentage of workers in alternative arrangements rose from $10.1 \%$ in 2005 to $15.8 \%$ in 2015 (Katz and Krueger, 2016). ${ }^{4}$ And such alternative arrangements are known for creating hard cases in grey areas between "employee" and "independent contractor", and sometimes blatant cases of deliberate misclassification. These difficulties have always been an inseparable part of the law, but they have exacerbated over the last three decades together with the proliferation of atypical, non-traditional (and usually precarious) work arrangements.

Given these ongoing difficulties, several scholars have argued that the distinction should be abolished and the protections afforded by labour law extended to independent contractors (and possibly others) as well (See, e.g., Carlson, 2001; Tucker, Fudge and Vosko, 2003). Others have also called for drastically expanding the scope of labour law (see, e.g., Langille, 2011). However, while it may well be justified to redraw the lines, some line-drawing is unavoidable when setting the scope of labour protections (as is often the case in law). Moreover, although by dramatically extending coverage (for example to all those who perform work for others) we can minimize problems of misclassification, such extension would also lead to diluting the standards themselves. If we offer the same level of protection to everyone, we can offer much less than what those workers really in need of protection might need. Imagine, for example, that the plumber or the tax consultant that you hire to help you occasionally will be treated as your employees, with the same rights that full-time employees of a large firm have via-a-vis that firm. It is easy to see how this will lead to lower standards: the expectations that society can have from the hirer of an occasional consultant are much lower than what we can expect from a business regularly employing workers. In short, re-drawing the lines is necessary; avoiding them altogether is problematic.

This leads to a second (and related) issue: should we maintain an "all or nothing" dichotomy? The distinction between employees and independent contractors has been described as a "binary divide" (Freedland and Kountouris, 2011: 104). In recent years it is becoming increasingly clear that such a crude dichotomy is insufficient to deal with the multitude of work arrangements and their nuances. A useful way to explain this is by reference to the spectrum of possibilities between universalism and selectivity (Davidov, 2014). A universal arrangement is one that applies to everyone; a selective arrangement is targeted only at specific groups. There are obvious advantages to a universal approach: most notably, it is much easier for people to know their rights (and for society to enforce them) when all employees or all workers have the same rights. In contrast, by using selective laws we can target a solution to a specific group (for example, a specific sector) that is more suitable for that group, sometimes at a higher or lower level of protection.

Mark Freedland and Nicola Kountouris (2011: 284-9) have argued in favour of a high degree of selectivity: different rights to different (numerous) groups. Some degree of selectivity is surely needed, especially if we want to expand protection to new groups. At the same time, we have to take into account the drawbacks as well. The challenge is to find the right balance between universalism and selectivity. One useful method towards an optimal balance is to add a third (intermediate) group between employees and independent contractors. One additional group should not make it too difficult for people to know their rights. At the same time, it will allow us to bring into the scope of protection workers who share only some of the characteristics of employees, and should be covered by some (but not all) labour and employment laws. Indeed, an intermediate group of "dependent contractors" (or some other name) al-

\footnotetext{
${ }^{4}$ The authors define alternative work arrangements as including temporary help agency workers, on-call worker, contract workers, and independent contractors or freelancers. This is quite a limiting definition, not including part-time, fixed-term, zero-hours and other arrangements. The point for current purposes is that the overall phenomenon is very significant, and growing.
} 
ready exists in many countries and its acceptance around the world is proliferating (Davidov, Freedland and Kountouris, 2015). When examining the best way to classify Uber drivers, in part IV below, I will therefore assume the possibility of an intermediate category as well.

A third preliminary question is whether we should leave the determination of "employee" status to judges. It is tempting to suggest that the question of "who is an employee" should be resolved with clear-cut answers in legislation or administrative regulations. It is indeed useful to create more determinacy by allowing workers in specific sectors to know their status. There have been some interventions of this kind in the United States with regard to Uber drivers. The city of Seattle has passed an ordinance allowing drivers of Uber and similar platforms to bargain collectively, whether they are otherwise considered employees or not. The ordinance faces legal and other challenges and in the meantime its entry into force has been delayed. ${ }^{5}$ Much more common are interventions in the other direction: some states have enacted legislation classifying Uber drivers as independent contractors, whether decisively (Indiana) or as a rebuttable legal presumption (South Dakota) or by listing several specific indicia that easily lead to this conclusion (Arkansas, Nevada). ${ }^{6}$

However, a proclamation that specific workers will be deemed employees or independent contractors notwithstanding any other result reached by the regular tests, cannot replace the tests themselves. This is an area in which some degree of indeterminacy is necessary. New forms of work appear all the time. If we set in legislation a specific list of criteria for clear-cut determination, it will be easy for employers to work around them and evade the law. To prevent evasion as much as possible and provide solutions for new work arrangements, it is necessary to leave a wide margin of discretion for courts. To be clear, this is not to say anything against regulations that deem groups of workers to be employees - whether conclusively or as a rebuttable legal presumption - as a solution for evasion problems in specific sectors. However, such solutions can lead employers to change the method of work organization, thus opening new uncertainties. At the end of the day, if our goal is first and foremost to ensure protection to those who need it, rather than ensure determinacy, some judicial discretion is unavoidable.

This leads us to the fourth and final preliminary issue. Given that we have labour laws that grant rights only to "employees", and as we have seen, generally speaking such a system - which excludes independent contractors, and relies on a degree of judicial discretion - makes sense, how should we interpret the term "employee"? There is growing consensus among courts in many countries that the term should be interpreted purposively: a term in legislation should be given a meaning that will best advance the purpose of that legislation. ${ }^{7}$ This seem to be - if applied correctly - the only sensible approach. So to decide who should be considered an "employee" we have to ask what are the goals (justifications) behind a specific law, or the goals behind the "project" of labour law as a whole (because at some level, all labour laws share the same basic purpose). As part of the need to balance between universalism and selectivity, I believe we should aim for a general understanding of "who is an employee", based on the project as a whole. Then we can also make adjustments, when necessary, in light of other/more specific goals of specific legislation.

Adopting a purposive approach will also allow us to expose problems that cannot be resolved by interpretation and require legislative amendments. For example, there are some specific protections for which the exclusion of independent contractors could be impossible to explain (i.e. for which the distinction as a whole seems unsuitable). It may also be the case that new forms of work require new

\footnotetext{
${ }^{5}$ For information on the ordinance see http://www.seattle.gov/council/issues/giving-drivers-a-voice and on the delay see http://seattle.ubermovement.com/seattle-ordinance/.

${ }^{6}$ The best source for up-to-date information on these developments (in the U.S.) is the blog www.onlabor.org. See, e.g., https://onlabor.org/2015/12/11/gig-news-uber-successfully-pursuing-state-legislation-on-independent-contractor-status/. See also http://www.iecoalition.org/blog/four-states-enact-laws-affecting-the-definition-of-independent-contractor/.

${ }^{7}$ See Autoclenz Ltd v Belcher [2011] UKSC 41 (UK Supreme Court); Pointe-Claire (City) v Quebec (1997) 1 SCR 1015 (Supreme Court of Canada); HCJ 4601/95 Sarusi v National Labor Court PD 52(4) 817 (1998) (Supreme Court of Israel); Konrad v Victoria Police (1999) 165 ALR 23 (Federal Court of Australia). The United States is an exception: although originally, its Supreme Court was a pioneer in adopting the purposive approach in this area (United States v Silk 331 US 704 (1947)), in more recent years conservative judges explicitly rejected this approach (Nationwide Mutual Insurance Co v Darden 503 US 318 (1992)). However, in the U.S. as well, some State courts adopted a purposive approach when interpreting State labour laws; see, e.g., S.G. Borello \& Sons, Inc. v. Department of Industrial Relations (1989) 48 Cal. 3d 341, recently applied with mention to this point in Cotter v. Lyft, Inc., 60 F. Supp. 3d 1067 (N.D. Cal. 2015).
} 
legal protections. For example, to the extent benefits are unnecessarily tied to a specific workplace and accumulate over time, this is becoming increasingly detrimental for people who work for short periods or for multiple employers. In other words, new forms of work such as "on demand" work - together with other alternative arrangements - should trigger rethinking of some existing laws and their suitability. Nonetheless, as far as the employee/independent contractor distinction in itself is concerned, a purposive approach ensures its suitability for "on-demand" workers: when we encounter new work arrangements such as these, we should not ask whether they are similar to "traditional" employment or not, but rather whether this is the kind of arrangement that requires the application of labour laws, given their purposes. In other words, if Uber drivers are in need of labour protection, purposive interpretation would ensure that they get it (assuming this is not explicitly prevented by legislation).

\section{A purposive approach}

In the previous part I advocated purposive interpretation of the term "employee" to set the scope of labour law. This is not an original position; other labour law scholars have adopted this approach before me. However, there was very little attempt to actually articulate the goals of labour law and derive conclusions for the appropriate "who is an employee" test. This is something I have engaged with for some time (see Davidov 2016); below is a very brief summary.

What does a purposive approach mean in practice, in the current context? Some have criticized it for being a case-by-case solution with no determinacy. It appears that some courts (for example in Israel) are adopting this approach: only after applying the "regular" tests, they ask in difficult cases whether the purpose of the law justifies the inclusion of the worker in question within the protected sphere. As a result, labour laws are applied on specific workers that appear to be vulnerable but were left out by the tests. While better than nothing at all, such an approach misses the point of purposive interpretation, which requires us to rethink the tests themselves. The tests were developed by courts, and they have to make sense in light of the goals of the legislation. If the tests lead to results that seem unwarranted, this is probably because they are not in tune with the purpose behind the law.

What is the purpose, then? A critical challenge is to choose the right level of abstraction or generality, in two respects. First, specific labour laws have specific goals. But there is also, as already noted, a general goal behind labour laws. If we want some degree of universalism, rather than complete selectivity (in which the meaning of "employee" is different for each and every law), we need to focus first on the general goal. Later, the scope of specific regulations can be amended, if needed, in line with more specific goals. As for the general goals, they can be articulated at different levels of abstraction. We can explain the need for labour laws in terms of the general values that they advance, such as equality, workplace democracy, distributive justice, autonomy, efficiency (more controversial), non-domination or maximizing capabilities. At another level, we can say that labour laws are needed to correct market failures or (most common) to address the inequality of bargaining power between employer and employee. Also, we can explain labour laws as addressing the vulnerabilities characterizing employment relations, which in my view are democratic deficits (or subordination, broadly conceived) and dependency.

The different articulations listed above do not contradict each other; they are all correct. The challenge is to choose the articulation that is most useful for current purposes, and this seems to be the latter one. If labour laws are needed to counteract subordination and dependency, they should cover workers who suffer from these vulnerabilities vis-à-vis an employer. And these characteristics are specific enough to allow us to make this determination, i.e. to identify those in need of protection (which is not possible with a vaguer concept such as inequality of bargaining power). Although one can certainly also argue that Uber drivers should be employees for reasons of distributive justice or non-domination (Rogers, 2016), this is not helpful to solve the next/other challenge. It is much better to identify ex-ante the kind of relationships that create a systematic disadvantage (vulnerability) in distributive and other respects. With this in mind, the different indicia used to identify employees can be re-examined, to consider if they are helpful and relevant in identifying the existence of subordination or dependency (I believe that only some of them are; see Davidov 2016: chapter 6). 
To clarify, this does not ignore the fact that specific pieces of legislation have other goals. The point is that they also share some basic reasoning: we need to intervene in the context of these market transactions (and not others), we need to protect workers under this kind of work arrangements (and not others), because of some basic characteristics that are unique (or stronger) in this exchange/relationship. Consider, for example, the California Family Rights Act, the California Wage Theft Protection Act, and the National Labor Relations Act - to give just a few diverse examples from the United States. Obviously they each have their own goals. But why do they all apply only to "employees" and exclude independent contractors? I suggest that the answer has to do with the vulnerabilities mentioned above. This leads us to a general interpretation of "employee" that can then be used at least as a starting point, before making it broader or narrower, if needed, in light of specific goals.

Generally speaking, the tests proposed here appear similar to those adopted by courts around the world. But there are a number of important differences. First, control (or subordination, the term usually used in Europe) is understood not in a technical way, but more broadly - the question is whether there is submission to commands or to rules of the organization, it the general sense of democratic deficits. Second, economic dependency is given more weight, and is similarly understood also in a broad sense - the question is whether the worker is in a position to spread risks. Third, dependency is not only economic, but also for the fulfilment of social and psychological needs. Finally, the more specific indicia are just aids to identify the two general vulnerabilities, and should be retained only if able to do so.

Should we require both subordination and dependency to determine that one is an employee? It appears that much of the labour law apparatus is designed to counteract dependency (and mostly economic). There are however some regulations designed to protect against subordination, and some concentrated on social/psychological dependency (the importance of work for the individual). Perhaps the easiest solution - in terms of minimizing upset of current laws - is to require some degree of both subordination and dependency for employee status - but extend current protections in two ways. First, the more a relationship is characterized by dependency, the less the worker will have to show subordination to be considered an employee. Second, at least some labour laws - probably most - should be extended also to workers in a position of economic dependency, even without any subordination, through an intermediate category of "dependent contractors". Thus, for example, the right to a minimum wage, and the right to bargain collectively, are both needed in situations of economic dependency, even without subordination.

\section{The Status of Uber Drivers: Applying the Tests}

We are now (finally) in a position to examine the status of Uber drivers. To what extent is there subordination (or democratic deficits, or "control" in a very broad sense) in the typical relationship between Uber and its drivers? Although people who work outside of a factory or an office obviously experience less direct control over their actions, it is not so unusual for businesses to employ people outside of clear geographical boundaries and still control them in different ways. Technology allows employers to maintain and strengthen such control. The facts indeed suggest that Uber drivers have to abide by detailed rules of the firm regarding the way they provide the service, and they are monitored at least to some degree through the app (see De Stefano, 2016: 491-3; Sachs 2015). The rating system in particular is a tool used to control the drivers by relying on feedback from customers about their performance. Moreover, the fact that drivers provide the Uber service to Uber customers on behalf of Uber suggests that they are integrated in the organization, explaining why a relatively high degree of control is necessary (poor service would harm Uber's reputation and its business vis-à-vis its customers; they are not the driver's customers).

The claim made by Uber in litigation that it is not a transportation company but only a technology company - and the drivers are its customers (or "partners") - has been rightly rejected by American and British courts alike (at least thus far, litigation is still ongoing). ${ }^{8}$ The London Employment Tribunal made

\footnotetext{
${ }^{8}$ In the U.S., see O'Connor v. Uber Technologies, Inc., 82 F.Supp.3d 1133 (N.D. Cal. 2015) (denying Uber's motion for summary judgment in a class-action suit filed by drivers); and see similarly Cotter v. Lyft, Inc., 60 F. Supp. 3d 1067 (N.D. Cal.
} 
this point most eloquently: "The notion that Uber in London is a mosaic of 30,000 small businesses linked by a common 'platform' is to our minds faintly ridiculous... Uber's case is that the driver enters into a binding agreement with a person whose identity he does not know (and will never know) and who does not know and will never know his identity, to undertake a journey to a destination not told to him until the journey begins, by a route prescribed by a stranger to the contract (UBV) [Uber] from which he is not free to depart (at least not without risk), for a fee which (a) is set by the stranger, and (b) is not known by the passenger (who is only told the total to be paid), (c) is calculated by the stranger (as a percentage of the total sum) and (d) is paid to the stranger... The absurdity of these propositions speaks for itself."'

The California courts which discussed whether control is present gave significant weight to the fact that Uber can terminate the relationship with a driver "at will" (without cause). ${ }^{10}$ This was seen as a leading indication of control (and accordingly of employment). But in fact arm's length business relations are even more characterized by the ability to leave at any time, which is a staple of the free market. Limitations on the ability to terminate do no say anything - one way or another - about the existence of subordination while the relationship exists. The fact that drivers work under a constant threat that Uber will terminate the relationship with them does not in itself suggest subordination/control. It is the fact that Uber uses the ratings given by customers and other information collected by the app to monitor drivers' actions and ensure that they abide by Uber rules that creates subordination. The background threat of termination in case of misbehaviour is important, but does not help to distinguish the relationship from other commercial relations (also characterized by the same constant threat).

While control over how drivers do their jobs appears to be quite significant, in contrast they have a relatively high degree of freedom to choose how much to work and when to do so. Notably, there are sometimes cases in which employers create the illusion of such freedom by drafting agreements which appear to give it to workers, even when in practice they work full time and on regular hours. ${ }^{11}$ In the Uber case as well, it has been noted that there are strong incentives to work more hours and in times of heavy demand, as dictated by the firm (Means and Seiner, 2016: 1542). Still, it seems that there is a degree of real freedom in this respect. ${ }^{12}$ This is a relevant consideration when examining the existence of control (or more broadly, democratic deficits/subordination) in the relationship. Being under the control of an employer explains, for example, the need for laws limiting the number of hours that one can be required to work. If a driver is free to decide for herself how many hours to work, at least in this particular respect the relationship is not characterized by control/subordination.

While I consider control of one's time a relevant indicator against employee status, I disagree with the view that this should be the main or only consideration (see Means and Seiner, 2016 for this view). Overall, the indications of subordination seem to outweigh the contrary indications. There is at least some degree of control/subordination in this relationship, which is one of the vulnerabilities justifying employee status. This also means that there is no reason to classify Uber drivers as dependent contractors (for a proposal along these lines see Harris and Krueger, 2015).

2015). In the U.K., see Aslam v. Uber, judgment of Oct. 28, 2016 (London Employment Tribunal) (accepting drivers' claim that they are "workers" for the purpose of UK labour laws). For an elaborated discussion of Uber's claim/narrative see Tomassetti, 2016. For a review of the litigation in the U.S. see Cherry, 2016. Although the drivers have been somewhat successful in their litigation in the U.S. - so far in lower courts - they are still facing a serious obstacle: the fact their contracts include arbitration clauses that place significant limitations on the ability of the drivers to challenge their status in court. Strangely, U.S. courts tend to enforce such contracts. See Stone, 2016, and see the recent decision in Mohamed v. Uber Technologoes, Inc. ( $9^{\text {th }}$ Cir., judgment of Sep. 7, 2016). It is this judicial policy that has led Uber drivers in the U.S. to agree to settle one major class-action suit by renouncing their claim for employee status in return for some cash and small changes to their standard contract. However, this settlement was so far rejected by the courts (see O’Connor v. Uber Technologies, Inc., judgment of Aug. 18, 2016 (N.D. Cal.)), so the legal situation of Uber drivers in the U.S. remains unclear. A settlement reached by Lyft (a competitor similar to Uber) with its drivers has been approved by another judge; see Cotter v. Lyft, Inc., judgment of June 23, 2016 (N.D. Cal.).

${ }^{9}$ Aslam v. Uber, note 8 above, pars. 90-91.

${ }^{10}$ O'Connor v. Uber, note 8 above; Cotter v. Lyft, note 8 above. In both cases the judgments relied on S.G. Borello \& Sons, Inc. v. Department of Industrial Relations (1989) 48 Cal. 3d 341 for this point.

${ }^{11}$ Zero-hour contracts are an obvious example; for a critical analysis see Adams, Freedland and Prassl (2015).

${ }^{12}$ Eisenbrey and Mishel (2016) convincingly refute the claim that the Uber drivers' working hours are immeasurable. But the fact that it is possible to measure the number of working hours does not contradict the fact that drivers are free to choose how many hours to work. 
With regard to economic dependency - which as a normative matter is even more important there are similarly strong indications supporting employee status. Most significantly, in my view, the firm is setting the cost of the ride and the payment to the driver unilaterally; the ability of drivers to influence the level of profit (other than by working more hours) is virtually non-existent; and drivers have almost no "entrepreneurial control" over business decisions. The main contrary indicator is the ownership of the car. To the extent one can use such equipment to spread risks, this is a sign of economic independence. Uber and similar platforms allow people to use an asset (their private car) to make an income in ways that were much more difficult in the past. The fact that the worker has control over this asset and can choose how to utilize it does indicate some independence.

An additional characteristic of Uber drivers that should be considered in this context is the fact that for many of them (though certainly not all; see Hall and Krueger, 2015) this is a "side gig" - they do this work only for a few hours per week. However, working only part-time (even a small part) does not seem material to our decision. If a driver is working with many different platforms - say a few hours per week with each platform - we can see this as spreading of risks and a sign of economic independence which should be taken into account. However, this is a different indicator - having numerous clientemployers - which could be a characteristic of some workers in the on-demand economy, but certainly not many of them. The mere fact that one is working part-time does not in itself indicate independence. When examining the existence/degree of dependence we should only be concerned with the ability to spread risks within the same line of work. The existence of other, irrelevant sources of income cannot be taken into account (otherwise workers will be seen as non-dependent and without access to employment rights if they have, for example, a rich spouse).

Overall, while taking into consideration the ownership of the car, there are stronger indications of economic dependency in this case. It appears, then, that both vulnerabilities are present and Uber drivers should be considered employees. The case seems difficult at first because of the combination of three characteristics that distinguish Uber drivers from "regular" employees: their freedom to choose how many hours and when to work; the ownership of the car used to provide the service; and the fact that many drivers work for a small number of hours per week. While neither of these characteristics is entirely new or unique to the "on-demand" economy, they all become much more possible and therefore common thanks to the new technologies; and their combination might create an impression that the drivers should be considered independent contractors. Nonetheless, a closer look, through the purposive framework outlined above, shows that one of these characteristics (number of hours) is irrelevant, and the other two are relevant for different questions, and each is outweighed by other indicators.

What does this mean for Uber (and similar companies)? If they have to treat drivers as employees, will they close up shop? There is no reason to believe so. Following labour laws can certainly be a hassle, and involve costs, but this is no different for any other business. They will have to adapt, for sure, for example by agreeing with each employee on a minimum number of hours (where the law requires such a commitment), as well as a maximum number of hours (to avoid paying wages when this is not justified economically by demand for rides). The cost of a ride is likely to be somewhat higher as a result, but this is not a reason, in itself, to abandon the entire model of connecting riders with drivers through an online platform. Society can enjoy the gains of technological advances and innovative businesses without accepting the evasion of labour laws.

\section{Conclusion}

Online platforms in which workers can be invited to work "on demand", with broad discretion given to the workers themselves to decide how much to work, present a new challenge for labour law. The age-old legal question of "who is an employee" has resurfaced with yet another reincarnation. Courts who formulate the answer to this question by reference to existing technical-legalistic tests may find the challenge insurmountable, meaning either that they will look for new tests altogether or simply decide that "on demand" workers are not employees. But if we adopt a purposive approach to determine who is an employee - as courts and scholars around the world increasingly do - the novelty of work 
arrangements does not divert us from asking the same question: should workers under this arrangement enjoy the protection of labour laws (all or some of them), given the goals of these laws? If the answer is positive, then they should be considered employees. In this respect, no new tests are needed; just an examination of the new factual situations in light of labour law's goals.

There can be different views, of course, about what these goals are, and specifically, about the most appropriate level of abstraction to articulate them. I have argued (based on previous writings) that subordination (in the sense of democratic deficits) and dependency (in the sense of inability to spread risks) are two vulnerabilities that characterize employment relations and provide a general explanation for why we need labour laws. Accordingly, to decide if one is an "employee" we have to ask whether the relationship vis-à-vis a potential employer is characterized by these two vulnerabilities. Even one of them should trigger at least some protection. But the existence of both vulnerabilities clearly points to the need to apply labour laws. The many tests (indicia) used in most legal systems to decide "who is an employee" can be used as aids, but only to the extent that they help to find whether subordination or dependency are present.

Online platforms are proliferating, thanks to advances in technology. They come in different shapes and forms, including a wide variety of work arrangements. It makes a big difference, for example, if the worker is free to decide her own hourly rate or rather has to accept the rates as set by the platform; if the worker is free to decide how to perform the work and for whom, or has to follow directions from the platform; and so on. My concrete examination in the current paper was limited to Uber drivers, and it appears on balance (after taking into account also contrary indications) that they should be considered "employees".

This is not to suggest that the "old" system of labour law is entirely suitable and sufficient to confront new work arrangements such as "on demand" work through platforms. When asking if these workers should be considered employees or not, a purposive approach leads us to answers. But a different question is whether the existing labour laws sufficiently address new problems faced by new models of work. In other words, the question of scope discussed in this paper is separated from the question of substance which also requires re-examination. Perhaps, for example, new protections are needed for employees working part-time vis-à-vis many different employers - that is, workers relying on multiple "gigs" - who might not be able to secure under current arrangements rights to vacations, overtime payments, pensions and more. Also, the question of what amounts to "working time" for purpose of minimum wage laws and working time laws requires a unique answer in the context of "on demand" workers. ${ }^{13}$ Finally, new protections could be needed for very small businesses that are not characterized by subordination and dependency on any single employer but still find it difficult to protect and insure themselves. Such challenges will have to be addressed in future research.

\section{Bibliography}

Adams, A., Freedland M. and Prassl, J. (2015). "The 'Zero-Hours Contract': Regulating Casual Work, or Legitimizing Precarity?", Oxford Legal Research Paper Series no. 11/2015.

Carlson R. R. (2001), "Why the Law Still Can't Tell an Employee When it Sees One and How it Ought to Stop Trying", Berkeley Journal of Employment and Labor Law, 22, 295-368.

Cherry, M. A. (2016), "Beyond Misclassification: The Digital Transformation of Work", Comparative Labour Law \& Policy Journal 37, 577-602.

DAvidov, G. (2014), “Setting Labour Law's Coverage: Between Universalism and Selectivity”, Oxford Journal of Legal Studies 34, 543-566.

Davidov, G. (2016), A Purposive Approach to Labour Law (Oxford: Oxford University Press).

Davidov, G., Freedland, M. and Kountouris, N. (2015). “The Subjects of Labor law: 'Employees' and Other Workers", in M. Finkin and G. Mundlak (eds), Research Handbook In Comparative Labor Law (Cheltenham: Edward Elgar), 115-131.

${ }^{13}$ The London Employment Tribunal was faced with this question in Aslam v. Uber, note 8 above, and concluded that any time the app is "on" and the driver is available for rides within the assigned territory is working time. 
Eisenbrey R. and Mishel L. (2016), "Uber Business Model Does Not Justify a New 'Independent Worker' Category”, Economic Policy Institute Report, available at http://www.epi.org/publication/uber-business-model-does-not-justify-a-new-independent-worker-category/.

FinkIN, M. (2016), "Beclouded Work, Beclouded Workers in Historical Perspective", Comparative Labour Law \& Policy Journal 37, 603-618.

Freedland, M. and Kountouris, N. (2011), The Legal Construction of Personal Work Relations (Oxford: Oxford University Press).

Hall J.V. and Krueger A.B. (2015), “An Analysis of the Labor Market for Uber's Driver-Partners in the United States", Princeton Industrial Relations Working Paper, available at http://dataspace. princeton.edu/jspui/handle/88435/dsp010z708z67d.

Harris, S.D. and Krueger, A.B. (2015), “A Proposal for Modernizing Labor Laws for Twenty-First Century Work: The 'Independent Worker'”, available at http://www.hamiltonproject.org/papers/ modernizing_labor_laws_for twenty_first_century_work_independent_worker.

Katz, L.F. and KRUeger A.B. (2016), "The Rise and Nature of Alternative Work Arrangements in the United States, 1995-2015”, Unpublished paper, available at http://scholar.harvard.edu/files/lkatz/ files/katz_krueger_cws_v3.pdf.

LangiLle, B. (2011). "Labour Law's Theory of Justice" in G. Davidov and B. Langille (eds), The Idea of Labour Law (Oxford: Oxford University Press).

Lobel, O. (2016), “The Law of the Platform”, Minnesota Law Review (forthcoming).

Means B. and Seiner J.A. (2016), "Navigating the Uber Economy”, U.C. Davis Law Review 49, 1511 1546.

Rogers, B. (2016), "Employment Rights in the Platform Economy: Getting Back to Basics", Harvard Law \& Policy Review 10, 479-520.

Sachs, Benjamin (2015), "Uber and Lyft: Customer Reviews and the Right-to-Control”, Onlabor blog, available at https://onlabor.org/2015/05/20/uber-and-lyft-customer-reviews-and-the-right-to-control/.

Signes, Adrián Todolí (2017), "The End of the Subordinate Worker? Collaborative Economy, On-demand Economy, Gig Economy, and the Crowdworkers' Need for Protection", International Journal of Comparative Labour Law and Industrial Relations (forthcoming).

De Stefano, V. (2016), “The Rise of the 'Just-in-Time Workforce': On-Demand Work, Crowdwork and Labour Protection in the "Gig-Economy"', Comparative Labour Law \& Policy Journal 37, 471-503.

Stone, K.V.W. (2016), "Uber and Arbitration: A Lethal Combination”, Economic Policy Institute, Working Economics Blog, available at http://www.epi.org/blog/uber-and-arbitration-a-lethal-combination/.

Tomassetti, J. (2016), "Does Uber Redefine the Firm? The Postindustrial Corporation and Advanced Information Technology", Hofstra Labor \& Employment Law Journal (forthcoming).

Tucker, E., Fudge, J. and Vosko L. (2003), "Employee or Independent Contractor? Charting the Legal Significance of the Distinction in Canada", Canadian Labour and Employment Law Journal, 10, 193-230. 